\title{
Effect of gestational weight gain on pregnancy outcome of Indian mothers
}

\author{
Keyur Patel, Megha Chaudhari, Maitri Shah*
}

Department of Obstetrics and Gynecology, Government Medical College, Baroda, Gujarat, India

Received: 07 February 2020

Accepted: 03 March 2020

*Correspondence:

Dr. Maitri Shah,

E-mail: maitrishah.gynec@gmail.com

Copyright: (C) the author(s), publisher and licensee Medip Academy. This is an open-access article distributed under the terms of the Creative Commons Attribution Non-Commercial License, which permits unrestricted non-commercial use, distribution, and reproduction in any medium, provided the original work is properly cited.

\begin{abstract}
Background: Gestational weight gain $(\mathrm{GWG})$ and pre-pregnancy body mass index (BMI) play important roles in determining the pregnancy outcome. The weight gain recommendations by the IOM are based on Western WHO BMI cut-offs, making it difficult to generalize their findings to Asian Indians. We aimed to compare GWG among healthy pregnant women across different BMI with the IOM guidelines-2009. We also aimed to evaluate associated fetomaternal outcomes with GWG among the pregnant women enrolled in the study.

Methods: A retrospective cohort study conducted at department of obstetrics and gynecology, from April 2019 to November 2019. Postnatal mothers whose weight was registered at first trimester of pregnancy and at term and delivered in SSG hospital were included. According to IOM Women were divided into: Group 1 less than recommended weight gain and Group 2 recommended weight gain.

Results: Significant difference was seen in the baby weight between the two groups ( $p$ value $<0.05$ ). 92.75\% of babies had low birth weight in Group 1 as compared to $42.21 \%$ in Group 2. On performing univariate logistic regression, significant association was seen between GWG and low birth weight $(p<0.05)$, no association was seen between GWG and caesarean ( $\mathrm{p}$ value $>0.05$ ), and no association was seen between GWG and preterm deliveries (p $>0.05)$.

Conclusions: Majority of patients in the both groups had term delivery. Women gaining less than recommended weight gain during pregnancy had new born with significantly lower birth weight. There was no association of mode of deliveries and GWG.
\end{abstract}

Keywords: Gestational weight gain, Indian, Pregnancy outcome

\section{INTRODUCTION}

Gestational weight gain (GWG) is an important determinant of pregnancy and birth outcome. ${ }^{1}$ The institute of medicine (IOM) pointed out the amount of appropriate GWG based on BMI before pregnancy and recommended to gain more weight in pregnant women with low BMI and less GWG in women with high BMI. ${ }^{2}$

Some studies have reported that excessive weight gain during pregnancy is related to an atypical increase in fetal growth, neonatal macrosomia, gestational diabetes mellitus and caesarean section while low GWG has been linked to a higher incidence of preterm delivery and LBW. ${ }^{3,4}$ One large study based on Indian participants has reported that Normal and overweight women who gained weight less than recommended have low risk for caesarean section and macrosomia. However, they have a higher (statistically insignificant) risk for low birth weight and preterm birth. it also shows that shows only $30 \%$ women gained weight as per IOM recommendation. ${ }^{5}$

So GWG can serve as an early marker for at-risk pregnancies. Most of the current evidence on BMI and GWG is from Western or high-income countries while 
data among women of developing countries like India is inadequate to generate recommendations. Given the importance of maternal pre-pregnancy anthropometric characteristics and GWG on pregnancy and birth outcomes, it is important to explore these factors in women of developing countries like India.

\section{METHODS}

This is a retrospective cohort study in postnatal mothers whose weight was registered at first trimester of pregnancy and at term and delivered in SSG hospital were included, Data related to height, weight, and GWG was noted. Women were divided into: Group 1 (those achieving less than the recommended weight gain) and Group 2 (those achieving equal to the recommended weight gain) were evaluated for inclusion in the study. Total 1104 women (in which 552 women in Group 1 and 552 women in Group 2) to estimate the difference of incidence of LBW by $4 \%$ ( $<$ IOM $8 \%$ assumption, $\geq$ IOM $4 \%$ assumption) with $80 \%$ power and $95 \%$ confidence interval were included over a time period of 1 year from April 2019 to November 2019.

\section{Inclusion criteria}

- Postnatal mothers whose height and weight are documented within first trimester pregnancy and at term or just before delivery

- Postnatal mothers with singleton pregnancy taken Antenatal care at SSGH and who delivered at SSG Hospital.

\section{Exclusion criteria}

- Postnatal mothers not giving consent to participate in the study

- Postnatal mothers having multiple gestation

- Postnatal mothers who is known case of cardiac disease, severe anemia, diabetes mellitus, chronic hypertension.

\section{Study procedure}

During the study period, after obtaining informed consent to be a part of the study, data from the case records of postnatal ward were collected in the proforma for all the postnatal mothers who fulfilled inclusion and exclusion criteria.

Weight and height and $1^{\text {st }}$ and $3^{\text {rd }}$ trimester weight were obtained from ANC case record and BMI was calculated according to that. Both weight measurements were to be done in ANC OPD on the same weighing scale (ScaleTech) by trained nursing staff. GWG was extracted from those records. All of them were divided in different BMI categories according to IOM classification.

In the present study, in terms of GWG, women were divided into two groups.
Group 1: Pregnant women achieving less than the recommended weight gain.

Group 2: Pregnant women achieving equal to the recommended weight gain.

All the mothers should have taken regular ANC and delivered at SSG hospital only.

The following details about delivery were noted from the case record.

- Mode of delivery (vaginal delivery/LSCS)

- Gestational age at delivery (term/pre term)

- Birth weight of baby (normal birth weight or LBW)

The outcomes of interest were weight of the baby, mode of delivery and time of delivery and GWG. Logistic regression will be done to control true confounding variables.

Confounding variables like maternal age, socioeconomic status, the number of previous gravidity and parity, number of previous caesarean sections were controlled using logistic regression model for data analysis.

\section{RESULTS}

In the present study, majority $(90.58 \%)$ of patients were in the age group of $21-30$ years. Only $4.26 \%$ of patients were $<=20$ years and $5.16 \%$ of patients belonged to 31 40 years. Mean value of age of study subjects was $25.95 \pm 3.02$ years (Table 1$)$.

Table 1: Distribution of age of study subjects.

\begin{tabular}{|c|c|c|}
\hline Age distribution in years & Frequency & $\%$ \\
\hline$<=20$ & 47 & $4.26 \%$ \\
\hline $21-30$ & 1000 & $90.58 \%$ \\
\hline $31-40$ & 57 & $5.16 \%$ \\
\hline Mean \pm SD & $25.95 \pm 3.02$ & \\
\hline Median (IQR) & $26(24-28)$ & \\
\hline
\end{tabular}

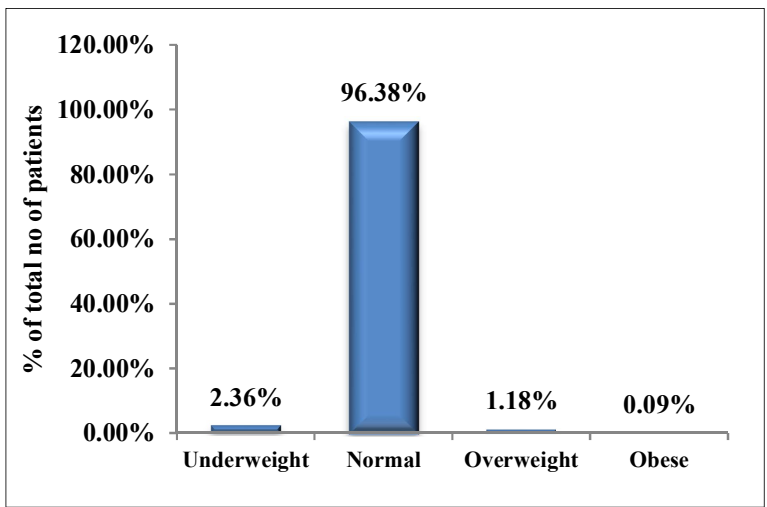

Figure 1: Distribution according to weight of study subjects. 
In the present study, majority $(96.38 \%)$ of patients had normal BMI. Only $2.36 \%$ of patients were underweight, $1.18 \%$ of patients were overweight and 1 out of 1104 patients was obese. Mean value of BMI, height and weight of study subjects was $21.19 \pm 1.73 \mathrm{~kg} / \mathrm{m}^{2}$, $156.36 \pm 6.65 \mathrm{~cm}$ and $51.88 \pm 5.6 \mathrm{~kg}$ (Table 2) (Figure 1).

Table 2: Distribution of anthropometric parameters of study subjects.

\begin{tabular}{|l|l|l|}
\hline Anthropometric parameters & Frequency & $\%$ \\
\hline \multicolumn{2}{|l|}{ Body mass index at admission } & $\left.\mathbf{( k g} / \mathbf{m}^{\mathbf{2}}\right)$ \\
\hline Underweight & 26 & $2.36 \%$ \\
\hline Normal & 1064 & $96.38 \%$ \\
\hline Overweight & 13 & $1.18 \%$ \\
\hline Obese & 1 & $0.09 \%$ \\
\hline Mean \pm SD & $21.19 \pm 1.73$ \\
\hline Median (IQR) & $21(19.900-22.300)$ \\
\hline Height (in cm) & \\
\hline Mean \pm SD & $156.36 \pm 6.65$ \\
\hline Median (IQR) & $157(151-161)$ \\
\hline Weight at 1 trimester & \\
\hline Mean \pm SD & $51.88 \pm 5.6$ \\
\hline Median (IQR) & $51.5(48.700-55.150)$ \\
\hline
\end{tabular}

In the present study, majority $(88.86 \%)$ of patients had term delivery. Preterm delivery occurred in only $11.14 \%$ of patients. Mean value of gestational age of study subjects was $38.57 \pm 1.24$ weeks (Table 3 ) (Figure 2).

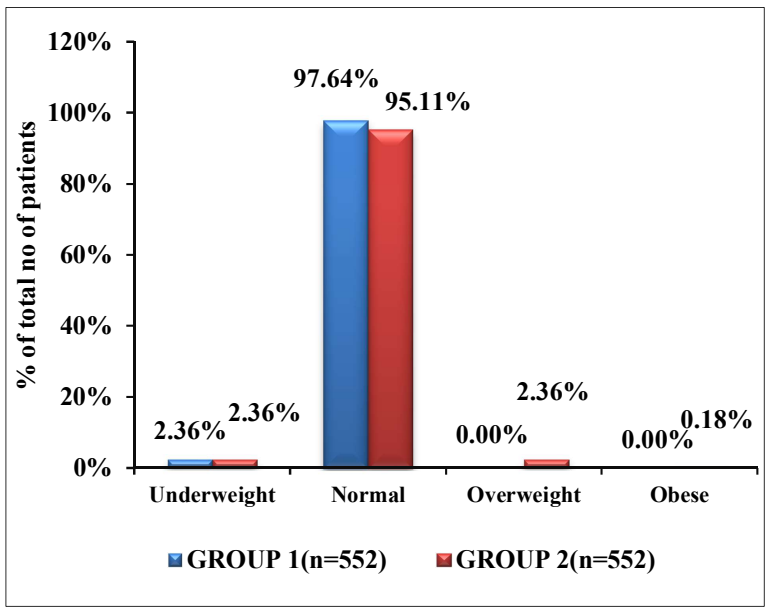

Figure 2: Comparison of body mass index at admission between Group 1 and Group 2.

On performing univariate logistic regression, no association was seen between gestational weight gain and caesarean ( $\mathrm{p}$ value $>0.05$ ). Risk of caesarean was comparable between patients who gained and who did not gain recommended weight (Table 4).

Table 3: Comparison of anthropometric parameters between Group 1 and Group 2.

\begin{tabular}{|c|c|c|c|c|}
\hline \multirow{2}{*}{$\begin{array}{l}\text { Anthropometric } \\
\text { parameters }\end{array}$} & \multicolumn{2}{|l|}{ Groups } & \multirow[b]{2}{*}{ Total } & \multirow{2}{*}{ p value } \\
\hline & Group $1(n=552)$ & Group $2(n=552)$ & & \\
\hline \multicolumn{5}{|c|}{ Body mass index at admission $\left(\mathrm{kg} / \mathrm{m}^{2}\right)$} \\
\hline Underweight & $13(2.36 \%)$ & $13(2.36 \%)$ & $26(2.36 \%)$ & \multirow{4}{*}{$0.003 *$} \\
\hline Normal & $539(97.64 \%)$ & $525(95.11 \%)$ & $1064(96.38 \%)$ & \\
\hline Overweight & $0(0.00 \%)$ & $13(2.36 \%)$ & $13(1.18 \%)$ & \\
\hline Obese & $0(0.00 \%)$ & $1(0.18 \%)$ & $1(0.09 \%)$ & \\
\hline Mean \pm SD & $20.98 \pm 1.55$ & $21.4 \pm 1.88$ & $21.19 \pm 1.73$ & \multirow{2}{*}{$0.001^{\#}$} \\
\hline Median (IQR) & $20.9(19.700-22)$ & $21.25(20.100-22.600)$ & $21(19.900-22.300)$ & \\
\hline \multicolumn{5}{|l|}{ Height (in cm) } \\
\hline Mean \pm SD & $156.05 \pm 6.41$ & $156.66 \pm 6.87$ & $156.36 \pm 6.65$ & \multirow{2}{*}{$0.17^{\#}$} \\
\hline Median (IQR) & $157(150-160)$ & $157(151-162)$ & $157(151-161)$ & \\
\hline \multicolumn{5}{|c|}{ Weight at 1 trimester } \\
\hline Mean \pm SD & $51.18 \pm 5.2$ & $52.57 \pm 5.89$ & $51.88 \pm 5.6$ & \multirow{2}{*}{$0.0002^{\#}$} \\
\hline Median (IQR) & $51.2(48.350-54)$ & $51.8(49.150-56.950)$ & $51.5(48.700-55.150)$ & \\
\hline
\end{tabular}

*Chi square test, \#Mann Whitney test (as the data set was not normally distributed so median was used for comparison).

Table 4: Univariate logistic regression to determine association of gestational weight gain with caesarean.

\begin{tabular}{|c|c|c|c|c|c|c|}
\hline & \multirow{2}{*}{ Beta coefficient } & \multirow{2}{*}{ Standard error } & \multirow{2}{*}{ p value } & \multirow{2}{*}{$\begin{array}{l}\text { Odds } \\
\text { ratio }\end{array}$} & \multicolumn{2}{|c|}{$95 \%$ CI for odds ratio } \\
\hline & & & & & Lower & Upper \\
\hline \multicolumn{7}{|c|}{ Recommended/less recommended } \\
\hline Less recommended & & & & 1.00 & & \\
\hline Recommended & 0.000 & 0.149 & 1.000 & 1.00 & 0.746 & 1.340 \\
\hline
\end{tabular}


Table 5: Univariate logistic regression to determine association of gestational weight gain with low birth weight.

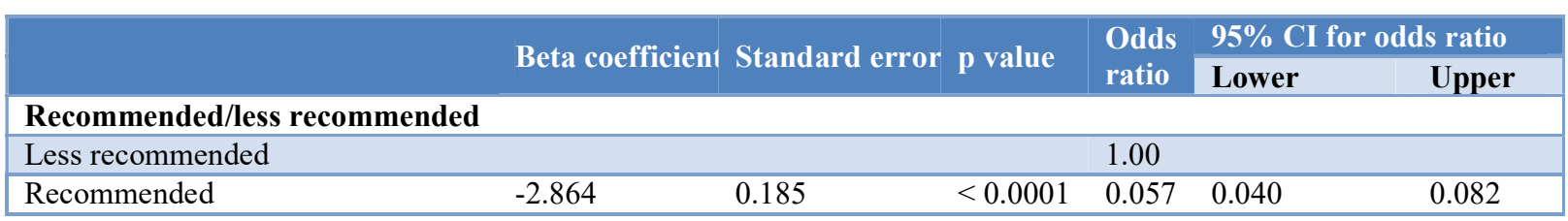

Table 6: Univariate logistic regression to determine association of gestational weight gain with preterm.

\begin{tabular}{|c|c|c|c|c|c|c|}
\hline & \multirow{2}{*}{ Beta coefficien 1} & \multirow{2}{*}{ Standard error } & \multirow{2}{*}{ p value } & \multirow{2}{*}{$\begin{array}{l}\text { Odds } \\
\text { ratio }\end{array}$} & \multicolumn{2}{|c|}{$95 \%$ CI for odds ratio } \\
\hline & & & & & Lower & Upper \\
\hline \multicolumn{7}{|c|}{ Group 1/Group 2} \\
\hline Group 1 & & & & 1.00 & & \\
\hline Group 2 & 0.202 & 0.192 & 0.293 & 1.224 & 0.840 & 1.783 \\
\hline
\end{tabular}

On performing univariate logistic regression, significant association was seen between gestational weight gain and low birth weight ( $\mathrm{p}$ value $<0.05$ ). Women who gained recommended weight had significantly $94.3 \%$ lower risk of low birth weight as compared to women who did not gain recommended weight with odds ratio of 0.057 (Table 5).

On performing univariate logistic regression, no association was seen between gestational weight gain and preterm ( $p$ value $>0.05$ ). Risk of preterm was comparable between patients who gained and who did not gain recommended weight (Table 6).

\section{DISCUSSION}

The role of GWG during the pregnancy holds an important role in the outcome of the pregnancy and neonate. The pre-pregnancy BMI is the basis to decide the adequate weight gain recommendation for the pregnant women.

Although there are standard IOM guidelines to assess and evaluate the maternal weight and recommended GWG, its application may be affected by the ethnicity and the country as the general built of women in developing and developed country differs.

There are very few studies on Indian women assessing the GWG and its effects on the feto-maternal outcomes. Thus, study did this study in the department of Obstetrics and Gynecology, postnatal ward of SSG hospital for a period of 8 months where a total of 1104 Postnatal mothers whose weight is registered at first trimester of pregnancy and at term and delivered in SSG hospital were assessed for GWG.

Compared to this study, Doherty in their study classified 331 women as underweight $(11.7 \%), 1982$ normal $(69.9 \%), 326$ overweight $(11.5 \%)$, and 188 as obese (6.6\%) Sebire studied a total of 287,213 completed singleton pregnancies which included 176, $923(61.6 \%)$ normal weight (BMI 20-24.9), 79, 014(27.5\%) moderately obese (BMI 25-29.9) and 31, 276(10.9\%) very obese $(\mathrm{BMI}>$ or $=30)$ women.

In another study by Waring et al, women had an average pre-pregnancy BMI of $25.2 \mathrm{~kg} / \mathrm{m}^{2}$ and gained an average of 33 pounds during pregnancy. Eighteen percent of women had inadequate GWG, 26\% gained appropriately, and $56 \%$ gained excessively. ${ }^{8}$

In an Indian study by Bhavadharini B et al, mean age of pregnant women was $27.4 \pm 4$ years, mean BMI was $25.1 \pm 4.8 \mathrm{~kg} / \mathrm{m}^{2}$, and mean weight gain during pregnancy was $8.8 \pm 4.8 \mathrm{~kg}$. It was seen that $30.5 \%$ of underweight, $23.4 \%$ of normal weight, $22.5 \%$ overweight, and $37.1 \%$ obese women met the recommendations for weight gain. While majority of underweight $(66.2 \%)$, normal weight women $(69.4 \%)$, and overweight women $(68.8 \%)$ gained weight less than recommended, among obese women, $28.5 \%$ of them gained more weight and $34.4 \%$ of them gained less than the recommended weight. ${ }^{5}$

On comparison between the women who gained recommended weight gain and those who gained less than recommended gestational weight, study found that significant difference was seen in the baby weight between the two groups ( $p$ value $<0.05$ ). 92.75\% of babies had low birth weight in less than recommended weight gain group as compared to $42.21 \%$ in recommended weight gain group. So, it can be concluded that incidence of low birth weight babies was significantly higher in women with less than recommended weight gain as compared to women with recommended weight gain. On performing univariate logistic regression, we found that women who gained recommended weight had significantly $94.3 \%$ lower risk of low birth weight as compared to women who did not gain recommended weight with odds ratio of 0.057 .

Apart from that we found no significant difference between the preterm/term distribution, mode of delivery and type of labor between the two groups ( $p$ value $>0.05$ ). 
Study findings were in line with Wills AK study who reported a higher percentage $(26 \%)$ of low birth weight infants among women who gained less weight than recommended. ${ }^{9}$ Compared to this study, Bhavadharini B et al found that normal weight and overweight women who gained less weight than recommended had statistically insignificant risk of both low birth weight and preterm birth. Underweight women are known to deliver preterm infants. In addition, underweight women gaining less weight than recommended can have high risk of delivering low birth weight infants as was seen in this study.

The mode of delivery such as caesarean section is usually influenced by several factors, such as practice behavior of the obstetrician or other pregnancy complications in obese women, may necessitate the need for cesarean section. Results from this study were in line with Edwards et al and Graham et al, who also found that when stratified by maternal weight gain, there was no significant association between GWG and cesarean section. $^{10,11}$ However, Seligman et al, reported that greater weight gain among during pregnancy was particularly associated with higher risk of cesarean sections. $^{12}$ Study reported no statistically significant association of GWG with preterm labor. Not many studies have reported on weight gain and its association to preterm labor. Study findings were in line with Zhong et al, who showed that association between GWG and preterm labor lacked statistical significance. ${ }^{13}$

Funding: No funding sources Conflict of interest: None declared

Ethical approval: The study was approved by the Institutional Ethics Committee

\section{REFERENCES}

1. Soltani H, Lipoeto NI, Fair FJ, Kilner K, Yusrawati Y. Pre-pregnancy body mass index and gestational weight gain and their effects on pregnancy and birth outcomes: a cohort study in West Sumatra, Indonesia. BMC Womens Health. 2017;17(1):102.

2. Weight gain during pregnancy - ACOG. Available at: https://www.acog.org/Clinical-Guidance-andPublications/Committee-Opinions/Committee-onObstetric-Practice/Weight-Gain-During-Pregnancy? IsMobileSet $=$ false. Accessed on $15^{\text {th }}$ January 2020.

3. Pugh SJ, Albert PS, Kim S, Grobman W, Hinkle SN, Newman RB, et al. Patterns of gestational weight gain and birthweight outcomes in the Eunice Kennedy Shriver National Institute of Child Health and Human Development Fetal Growth Studies-
Singletons: a prospective study. Am J Obstet Gynecol. 2017;217(3):346.e1-346.e11.

4. Omani-Samani R, Sepidarkish M, Safiri S, Esmailzadeh A, Vesali S, Farzaneh F, et al. Impact of gestational weight gain on cesarean delivery risk, perinatal birth weight and gestational age in women with normal pre-pregnancy BMI. J Obstet Gynecol India. 2018;68(4):258-63.

5. Bhavadharini B, Anjana RM, Deepa M, Jayashree G, Nrutya S, Shobana M, et al. Gestational weight gain and pregnancy outcomes in relation to body mass index in Asian Indian women. Indian $\mathrm{J}$ Endocrinol Metab. 2017;21(4):588-93.

6. Doherty DA, Magann EF, Francis J, Morrison JC, Newnham JP. Pre-pregnancy body mass index and pregnancy outcomes. Int $\mathrm{J}$ Gynecol Obstet. 2006;95(3):242-7.

7. Sebire NJ, Jolly M, Harris JP, Wadsworth J, Joffe M, Beard RW, et al. Maternal obesity and pregnancy outcome: A study of 287213 pregnancies in London. Int J Obes. 2001;25(8):1175-82.

8. Waring ME, Moore Simas TA, Liao X. Gestational weight gain within recommended ranges in consecutive pregnancies: a retrospective cohort study. Midwifery. 2013;29(5):550-6.

9. Wills AK, Chinchwadkar MC, Joglekar CV, Natekar AS, Yajnik CS, Fall CHD, et al. Maternal and paternal height and BMI and patterns of fetal growth: The Pune Maternal Nutrition Study. Early Hum Dev. 2010;86(9):535-40.

10. Edwards LE, Hellerstedt WL, Alton IR, Story M, Himes JH. Pregnancy complications and birth outcomes in obese and normal-weight women: effects of gestational weight change. Obstet Gynecol. 1996;87(3):389-94.

11. Graham LE, Brunner Huber LR, Thompson ME, Ersek JL. Does amount of weight gain during pregnancy modify the association between obesity and cesarean section delivery? Birth. 2014;41(1):93-9.

12. Seligman LC, Duncan BB, Branchtein L, Miranda Gaio DS, Mengue SS, Schmidt MI. Obesity and gestational weight gain: cesarean delivery and labor complications. Rev Saude Publica. 2006;40(3):457-65.

13. Zhong Y, Cahill AG, MacOnes GA, Zhu F, Odibo AO. The association between pre-pregnancy maternal body mass index and preterm delivery. Am J Perinatol. 2010;27(4):293-8.

Cite this article as: Patel $\mathrm{K}$, Chaudhari $\mathrm{M}$, Shah $\mathrm{M}$. Effect of gestational weight gain on pregnancy outcome of Indian mothers. Int J Reprod Contracept Obstet Gynecol 2020;9:1681-5. 